\title{
Correction to: Genetic association of vascular endothelial growth factor (VEGF) gene variants with the risk for diabetic retinopathy: a meta-analysis
}

\author{
Sanober Kafeel ${ }^{1}$ D $\cdot$ Khan Muhammad Nangrejo $^{2} \cdot$ Roberto Gonzalez-Salinas $^{3}$ (D)
}

Published online: 3 January 2022

(c) The Author(s), under exclusive licence to Research Society for Study of Diabetes in India 2021

Correction to: International Journal of Diabetes in Developing Countries (2021) 41:180-188 https://doi.org/10.1007/s13410-020-00874-9

Out of them, $n=189$ studies contained duplicated data.

Flowchart represents the assessment criteria of inclusion and exclusion.

The original article can be found online at https://doi.org/10.1007/ s13410-020-00874-9.

Sanober Kafeel

sanoberkafee193@gmail.com

Khan Muhammad Nangrejo

Knangrejo@gmail.com

Roberto Gonzalez-Salinas

dr.gonzalezsalinas@apec.com.mx

1 Karachi Institute of Biotechnology and Genetic Engineering (KIBGE), University of Karachi, Karachi 75270, Pakistan

2 Department of PMC Hospital, Peoples University of Medical $\&$ Health Sciences for Women, Shaheed Benazirabad, Nawabshah 67480, Sindh, Pakistan

3 Asociacion para Evitar la Ceguera en México (APEC), Vicente García Torres 46, San LucasCoyoacán, 04030 Ciudad de Mexico, Mexico 

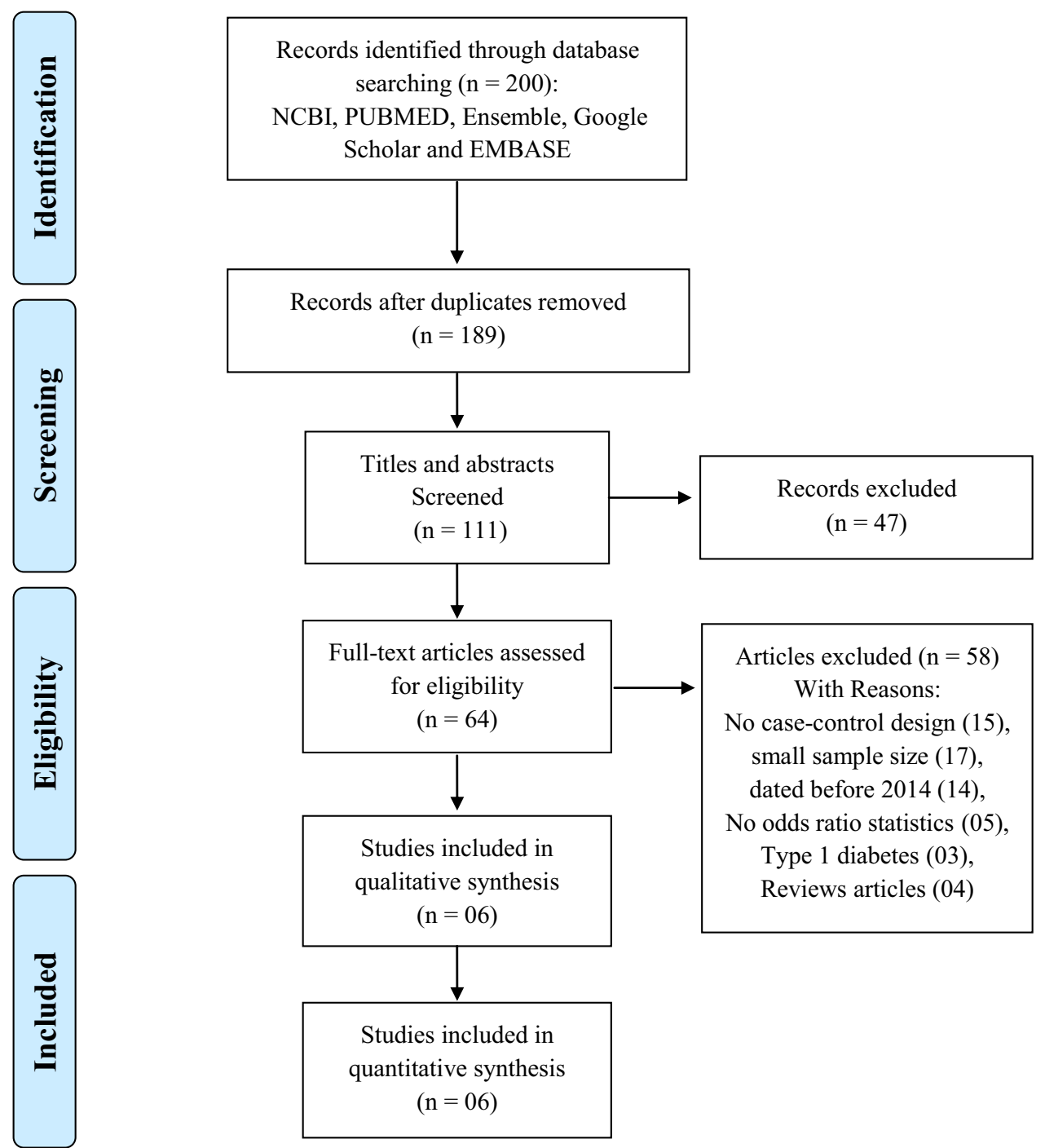

Publisher's Note Springer Nature remains neutral with regard to jurisdictional claims in published maps and institutional affiliations. 